$\frac{12}{9-1-9582(1)}$

UCRL-ID-120398

\title{
Preliminary Investigation of Grain Refinement in a U-0.2 w/o V Alloy Casting by True Isothermal Transformation at $516^{\circ} \mathrm{C}$
}

David H. Wood

Randolph Flores

Robert P. Kershaw

July 1995

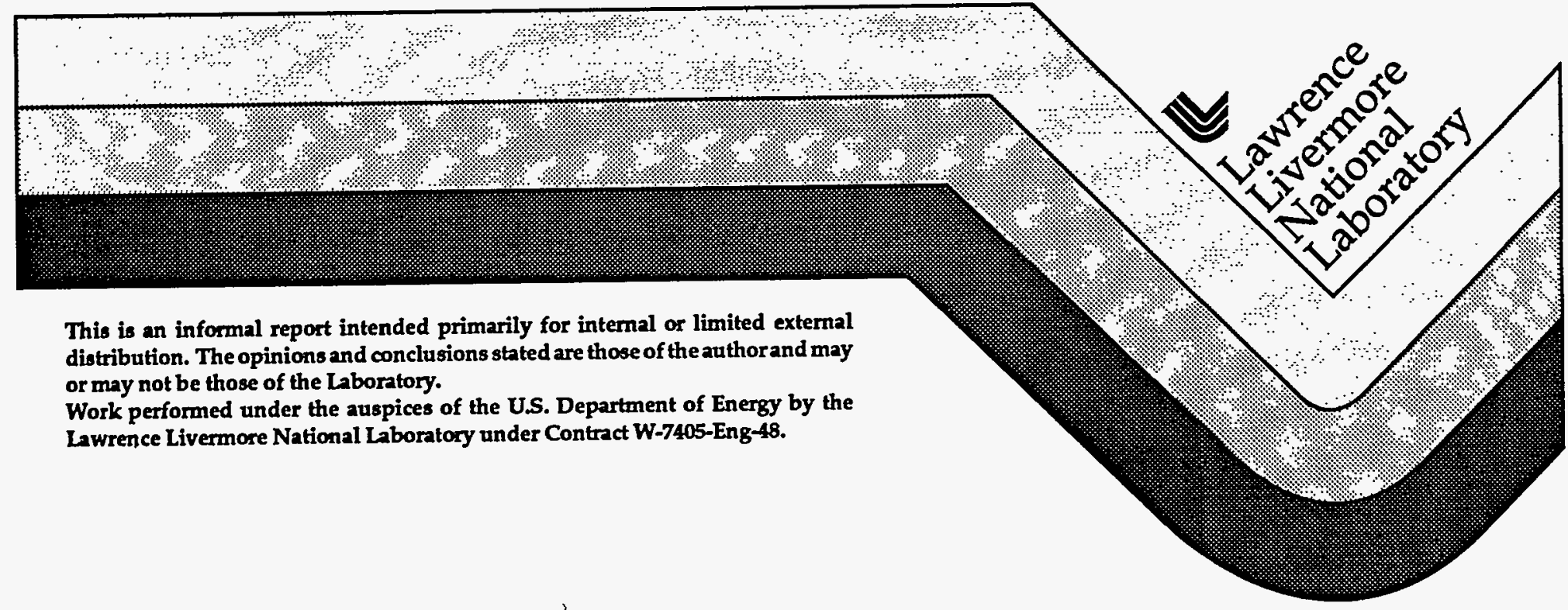




\section{DISCLAIMER}

This document was prepared as an account of work sponsored by an agency of the United States Government. Neither the United States Government nor the University of California nor any of their employees, makes any warranty, express or implied, or assumes any legal liability or responsibility for the accuracy, completeness, or usefulness of any information, apparatus, product, or process disclosed, or represents that its use would not infringe privately owned rights. Reference herein to any specific commercial products, process, or service by trade name, trademark, manufacturer, or otherwise, does not necessarily constitute or imply its endorsement, recommendation, or favoring by the United States Government or the University of California. The views and opinions of authors expressed herein do not necessarily state or reflect those of the United States Government or the University of California, and shall not be used for advertising or product endorsement purposes.

This report has been reproduced directly from the best available copy.

Available to DOE and DOE contractors from the Office of Scientific and Technical Information

$$
\text { P.O. Box 62, Oak Ridge, TN } 37831
$$

Prices available from (615) 576-3401, FTS 626-8401

Available to the public from the

National Technical Information Service

U.S. Department of Commerce

5285 Port Royal Rd.

Springfield, VA 22161 


\section{DISCLAIMER}

Portions of this document may be illegible in electronic image products. Images are produced from the best available original document. 


\section{Preliminary Investigation of Grain Refinement}

in a U-0.2 w/o V Alloy Casting by True Isothermal Transformation at $516^{\circ} \mathrm{C}$

July 1995

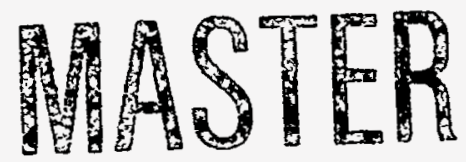

DISTRIBUTION OF THIS DOCUMENT IS UNLIMITED 


\section{Preliminary Investigation of Grain Refinement in a U-0.2 w/o V Alloy Casting by True Isothermal Transformation at $516^{\circ} \mathrm{C}$}

\section{Summary}

Laboratory-scale isothermal transformation from beta phase to alpha phase at $516^{\circ} \mathrm{C}$ was accomplished using one $\mathrm{U}-0.2 \mathrm{wt} \% \mathrm{~V}$ alloy composition and with specimens up to $7.6 \mathrm{~mm}$ in thickness. Gravity was used to transfer individual specimens from a furnace at $720^{\circ} \mathrm{C}$ to one at $516^{\circ} \mathrm{C}$. The lower-temperature furnace contained two copper blocks between which the specimens were quenched by contact. The furnace also contained a partial atmosphere of helium. The results duplicate those of Reisse et al. ${ }^{1}$ at this temperature. Their work was done on smaller samples. Grain sizes obtained were consistently ASTM 7 to $8(20$ to $30 \mu \mathrm{m})$, indicating that the cooling rates at the center of even the thicker samples were adequate to miss the nose of the (upper) TTT curve. The microstructure obtained, including the grain size, appears to be equivalent to that obtained by carefully controlled wrought processing, but we believe these castings lack the strong crystallographic textures that exist in wrought products.

\section{Background}

The work of Reisse et al. ${ }^{1}$ and many other papers from France describe the metallurgy of uranium-vanadium alloys in great detail. The purpose of vanadium is to allow the grain size of the as-cast uranium to be refined by appropriate heat treatments. In our laboratory, we have previously heat-treated cast $\mathrm{U}-\mathrm{V}$ alloy for practical application by controlled cooling. ${ }^{2}$ That work produced a grain size of about $70 \mu \mathrm{m}$. In the present work, we were requested to improve the heat treatment to the extent that the final grain size would be about $20 \mu \mathrm{m}$, comparable with carefully produced wrought uranium. The work of Reisse et al. ${ }^{1}$ indicates that the way this might be accomplished is by-an isothermal transformation at about $516^{\circ} \mathrm{C}$.

Reisse's work, ${ }^{1}$ being scientific in nature, used thin specimens and severe quenches into a molten lead-tin bath to establish the position of the time-temperature-transformation curve for this material. This curve is commonly referred to as a " $\mathrm{C}$-curve" because of its shape as traditionally plotted. C-curves result from nucleation and growth considerations that are described in detail by Christian. ${ }^{3}$ Few crystal nuclei and high growth rates result in long transformation times and large grains just below a transformation temperature. Lower temperatures result in many crystal nuclei, but slow growth for long transformation time resulting in very fine grain sizes. Between these two temperatures, the transformation times are short because there is an optimum combination of nuclei and growth rate for a transformed crystal. This optimum (highest) rate of transformation is called "the nose of the C-curve." Figure 3 in the paper by Reisse et al. shows this nose for the initiation of the beta-to-alpha transformation at about $15 \mathrm{~s}$ and at $560^{\circ} \mathrm{C}$. It is believed that the action of the vanadium in solution in this alloy is to retard this transformation from that which would be the case for unalloyed uranium. Thus, this shift to 
longer transformation times ( $15 \mathrm{~s}$ at the nose) allows time to cool the alloy to a lower temperature, produce many new crystal nuclei, and have many small grains as a result; i.e., the vanadium allows one to miss the nose of the $\mathrm{C}$-curve and transform through the lower portions of that curve.

There is also a low temperature transformation in this, and many other, uranium alloys. This has been characterized as a martensitic reaction in some systems and as a C-curve in others. The work of Reisse et al. ${ }^{1}$ shows the microstructure of this low-temperature transformation product as produced at $503^{\circ} \mathrm{C}$ and below. Because of the jagged grain boundaries, larger grain size, and different appearance from the equiaxed grains of recrystallized wrought uranium, we have assumed that this is not a desired microstructure. The tersile data of Reisse show elongations of 5.4 and $7.5 \%$ in a 55-ppm carbon-2100-ppm V alloy cooled at $230^{\circ} \mathrm{C} / \mathrm{min}$. (See Reisse et al., ${ }^{1}$ Table II.) With subsequent annealing, the mechanical properties improve. Work at Y-12 has also shown that beta-quenching and alpha annealing, which has been used for other "adjusted" uranium, is not an advantageous heat treatment for uranium-low-vanadium alloys. ${ }^{4}$ Indeed, one of the most important advantages of the U-V alloy is that very fine grain sizes can be obtained in castings without resorting to severe quenches to room temperature.

\section{Experimental Methods}

The uranium-vanadium used in these experiments was obtained from only one melt and has been previously described. ${ }^{2}$ It was obtained from the riser of 3390-71-3800, a part cast for us at the Y-12 Plant of Martin-Marietta Nuclear Corp. in Oak Ridge, Tennessee.

The composition of this casting was reported to us by $\mathrm{Y}-12$ personnel and is shown in Table I.

Samples cut from this material were discs $19 \mathrm{~mm}(0.75$-in.) in diameter and varied in thickness between $2.5 \mathrm{~mm}(0.10$-in.) and $7.6 \mathrm{~mm}(0.3$-in.). Two series were made. The first series had

Table I. Composition of the material used.

Uranium

Vanadium

Carbon

Iron

Silicon

Titanium

Nickel

Copper

Aluminum
Balance

0.20 wt\%

63 wppm

$<10$ wppm

$<10$ wppm

10 wppm

8 wppm

4 wppm

10 wppm 
straight cylindrical edges, and the thicker specimens were prone to stand on edge after a drop onto a flat surface. To be sure every sample would fall into a flat position, the thicker specimens in the second series had rounded edges. These samples were all machined in a lathe to a surface finish estimated to be about 63 micro-inches.

\section{Furnaces and Their Operation}

To change the temperature of the sample from 720 to $516^{\circ} \mathrm{C}$ as rapidly as possible, and without undercooling, a special experimental apparatus was constructed. This apparatus is shown in Figure 1 and consists of two different tube furnaces mounted vertically at different elevations. The furnace tubes were made of stainless steel and were interconnected in such a way that a specimen could be released from the upper furnace and fall into the lower one. Both furnaces had copper blocks in the hot zones.

The block in the upper furnace had a vertical slot cut into the bottom of the copper. This slot was large enough to accommodate the largest anticipated sample. A tantalum door, which was rotated with a vertical tantalum rod, held the sample in the slot until the door was rotated to allow the sample to fall into the lower furnace.

In the lower furnace, the copper block was divided in half by a horizontal cut. The upper piece could be lifted vertically up through a branch in the furnace tube by means of a rod that slid through a vacuum seal. This upper copper piece was, when lifted, high enough to allow the sample to fall into place between the two halves of the copper block in the lower furnace. This was possible by introducing the falling sample through a tube that sloped at about $45^{\circ}$ vertically. After the sample fell, the uppermost piece of copper in the lower furnace was quickly returned into the hot zone, sandwiching the sample between the two pieces of copper, both of which were at a nominal $516^{\circ} \mathrm{C}$.

The samples were held at $516^{\circ} \mathrm{C}$ for 3 hours and then cooled in the furnace with the power off. The furnace tube was integral between the furnaces and was attached to a vacuum pump and a source of helium. During the drop and quench, the helium pressure was always two-thirds of an atmosphere absolute. Thermocouples were emplaced in the copper blocks in each furnace, but they were not actually touching the sample in the lower furnace and could not detect transformations. The apparatus and experiment were designed to find just how thick a sample could be isothermally transformed by "tool quenching" between the copper blocks, and no means of detecting the onset or completion of transformation to establish a C-curve was provided.

\section{Planning the Experiments}

In planning these experiments, we considered the possible use of heat transfer codes to predict the results. However, we decided that we would have to do the experiments anyway to be sure what the results would be. There were several assumptions which would be required input into the codes: the position of the curve might change from that of the French alloy, and the transfer 
coefficients at the interface between the copper and the uranium would have to be estimated. Therefore, we relied on our intuition that we probably would see relatively large grains in the center of the 7.6-mm-thick (0.3-in.-thick) specimens. Our intuition was wrong.

\section{Results}

We had quenched all specimens in the first series one at a time. The 7.6- $\mathrm{mm}$ specimen landed on edge as indicated by the position of the handle attached to the upper $516^{\circ} \mathrm{C}$ copper block during the quench. There were five of these specimens, each of a different thickness. All these specimens and all locations in all specimens exhibited a very fine grain size between ASTM 7 and ASTM 8 (20 to $30 \mu \mathrm{m}$ average intercept), including the one standing on edge. The same identical results were obtained in the second series where all specimens fell flat between the quench blocks. Photomicrographs typical of these specimens are shown in figure 2. In addition to the photomicrographs, which all appeared practically identical, we searched the polished through-the-center sections of these samples under the microscope for regions that might exhibit different grain sizes or microstructures. None were found.

\section{Discussion}

The results indicate that with this one alloy composition, it is quite easy to accomplish the isothermal transformation and it has the potential to be used as a production method to make parts up to at least 7-mm thick, and probably thicker, with grain sizes equivalent to wrought product. Apparently, all of the material quenched (even the center of the thick sample standing on edge) was cooled fast enough to miss the nose of the C-curve and subsequently transform in a true isothermal manner at $516^{\circ} \mathrm{C}$. This is the explanation for the observation of the uniform microstructure and grain size and is very encouraging with regard to the ease of scaling this process up for larger castings.

\section{Future Work}

As various melts of $\mathrm{U}-\mathrm{V}$ alloy become available, they will show a variation in composition. Iron and silicon contents will range upward from the material tested, and both carbon and vanadium contents will vary. We plan to continue these simple experiments on such material to determine if variations in composition make significant differences in the results. If they do not, then some method should be devised to scale up from the laboratory experiments to allow heat treatment of larger castings.

\section{Acknowledgment}

This work was funded and supported by B-Program. We are grateful for the support provided by the Y-12 Plant. 


\section{References}

1. R. Reisse, C. Collot, C. de Lamer, C. Guillaume, and D. Francois, "Contribution to the Study of Uranium Alloys with a Low Vanadium Content," Memoires Scientifiques Rev. Metallurg. LXIV(5), 453-466 (1967).

2. D. H. Wood, M. W. Wraith, and G. F. Gallegos, Discussions Regarding the Cast Uranium Shell in Hydroshot 417B (U), UCRL-ID (SRD), Lawrence Livermore National Laboratory, in preparation.

3. J. W. Christian, The Theory of Transformations in Metals and Alloys, Pergamon Press, pp. 489-495 (1965).

4. R. C. Anderson and P. A. Evans, Evaluation of Heat-Treated Cast Uranium and Uranium-Low Vanadium Alloys (U), Y-12 Report Y-2141-3 (SRD), pp. 55-62. 


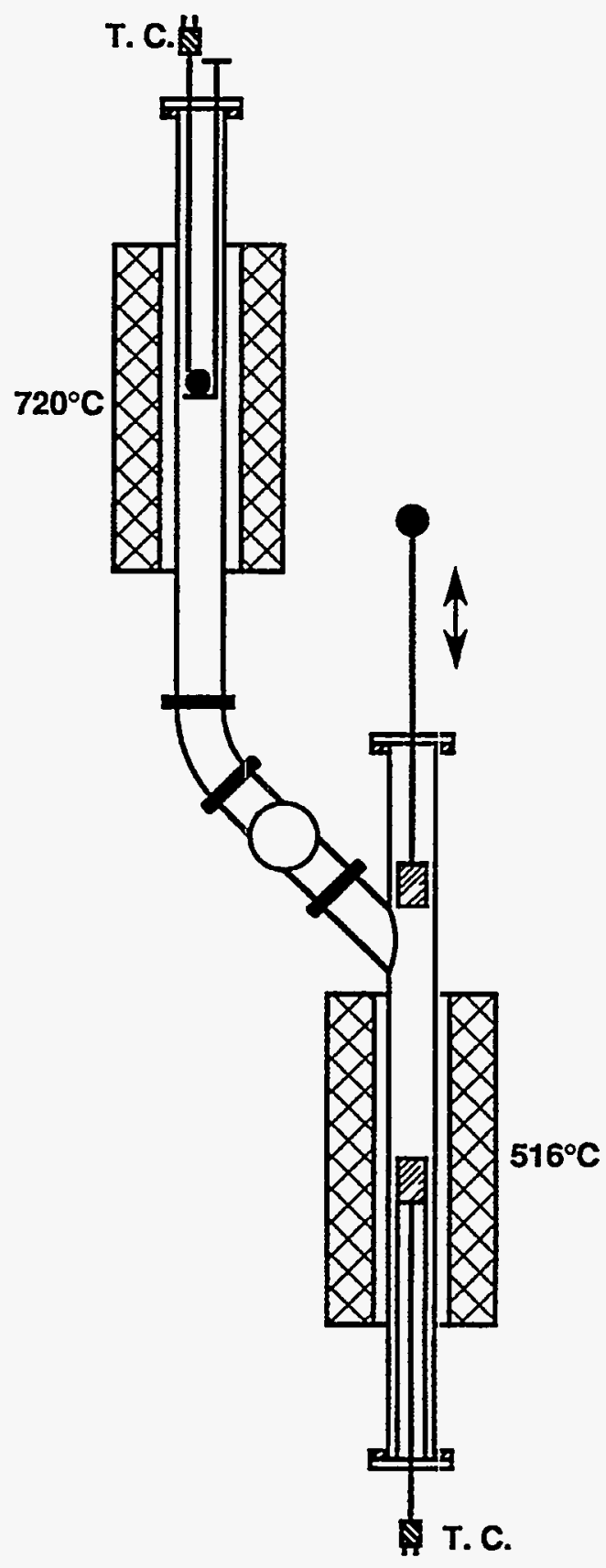

Figure 1. Schematic drawing of the experimental isothermal quenching furnaces. 
(a)

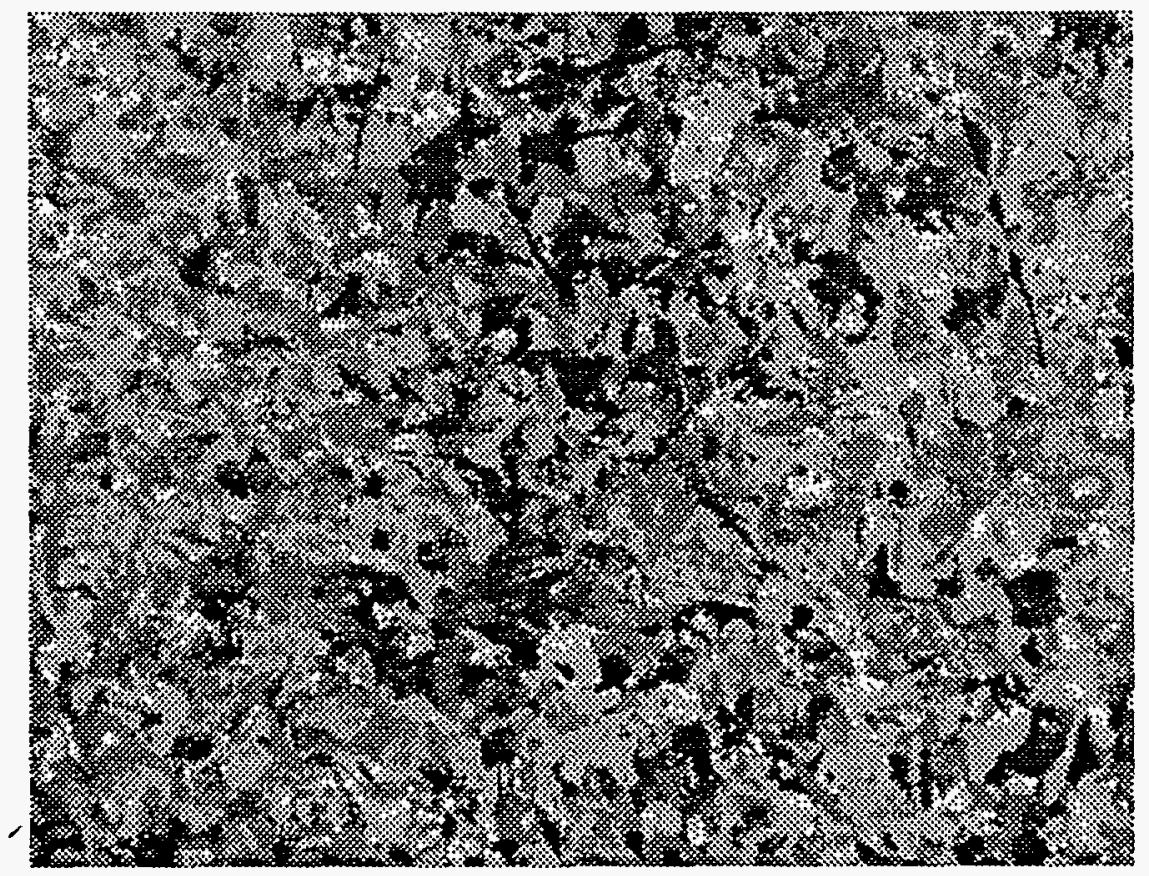

(b)

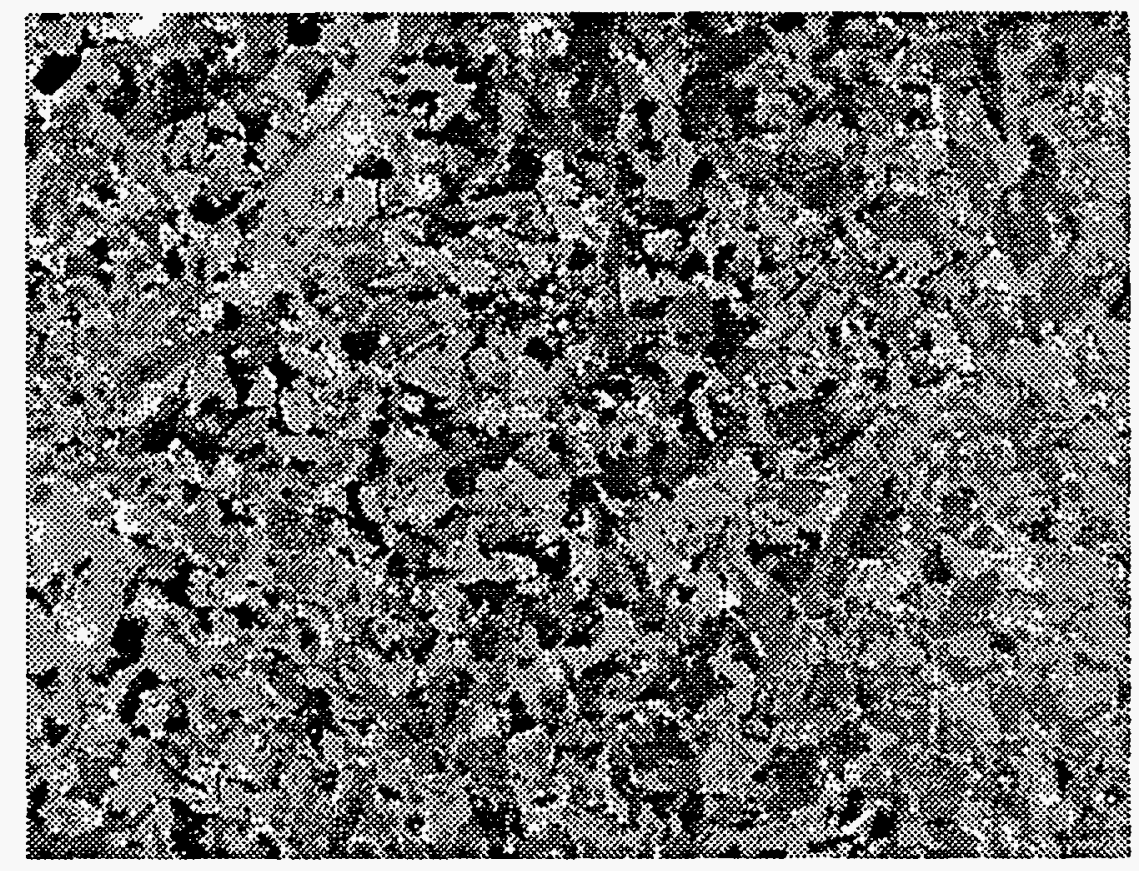

Figure 2. Microstructures typical of those obtained by true isothermal transformation at $516^{\circ} \mathrm{C}$ : (a) from a sample 0.250-in. thick and (b) from a sample 0.300-in. thick. All of our transformed material looked just like this. 100x (polarized light). 